\title{
A COMPARATIVE STUDY BETWEEN WMMS AND TLS FOR THE STABILITY ANALYSIS OF THE SAN PEDRO CHURCH BARREL VAULT BY MEANS OF THE FINITE ELEMENT METHOD
}

\author{
L.J. Sánchez-Aparicio ${ }^{1,}{ }^{*}$, B. Conde ${ }^{2}$, M. A. Maté-González ${ }^{1}$, R. Mora ${ }^{1}$, M. Sánchez-Aparicio ${ }^{1}$, J. García-Álvarez ${ }^{3}$, D. González- \\ Aguilera $^{1}$ \\ ${ }^{1}$ Department of Cartographic and Land Engineering. University of Salamanca, Higher Polytechnic School of Ávila, Hornos Caleros, \\ Ávila, Spain - (luisj, mategonzalez, rociomora,mar_sanchez1410, daguilera) @usal.es \\ ${ }^{2}$ University of Vigo, School of Industrial Engineering, Department of Engineering Materials, Applied Mechanics and Construction, \\ Vigo, Spain - bconde@uvigo.es \\ ${ }^{3}$ Fundación Santa María la Real del Patrimonio Histórico, Aguilar de Campoo, Palencia, Spain - j.garcia@santamarialareal.org
}

\section{Commission II, WG II/8}

KEYWORDS: Wearable Mobile Mapping System, Terrestrial Laser Scanner, Masonry, Historical Constructions, Finite Element Method, Structural Analysis

\begin{abstract}
:
Stability of masonry constructions is highly conditioned by the geometric disposition of its elements due to its low tensile strength and great compressive mechanical properties. Under this framework, this paper attempts to evaluate the suitability of a wearable mobile mapping solution, equipped in a backpack and based on the well-known simultaneous location and mapping paradigm, for the structural diagnosis of historical constructions. To evaluate the suitability of this device, the structural analysis obtained is compared with a high precision terrestrial laser scanner, which is considered as ground truth. The Romanesque church of San Pedro (Becerril del Carpio, Spain) was selected as a study case. This construction, initially conceived in the XIII ${ }^{\text {th }}$ century, has experimented in the past a soil settlement promoting the leaning of the north wall, several plastic hinges in its barrel vault and a visible geometrical deformation. The comparison of both techniques was carried out at different levels: i) an evaluation of the time needed to obtain the point cloud of the church; ii) an accuracy assessment based on the comparison of a terrestrial network using artificial spheres as checkpoints and; iii) an evaluation of the discrepancies, in terms of safety factor and collapse topology, found during the advance numerical evaluation of the barrel vault by means of the finite element method. This comparison places this wearable mobile mapping solution as an interesting tool for the creation of advanced numerical simulations to evaluate the structural stability of historical constructions.
\end{abstract}

\section{INTRODUCTION}

Modern restoration standards, based on the principles exposed by the last International Charter of Restoration (Charter of Krakow, 2000), highlight the necessity of carrying out multidisciplinary studies to understand historical building from different points of view, i.e., constructive or historical. Within this multidisciplinary context, the Terrestrial Laser Scanner (TLS) has been placed as a potential tool being possible to evaluate the presence of different degradation processes (Del Pozo et al., 2016; Sánchez-Aparicio et al., 2018), as well as to provide the geometrical framework required for the evaluation of its structural stability (Bautista-De Castro et al., 2018; Sanchez-Aparicio et al., 2019). However, these approaches lack efficiency when the complexity of the building increases and many TLS stations are required, demanding massive field campaigns that entail important errors propagation.

In contrast with this, the recent developments in the field of remote sensing and robotics navigation have allowed the digitalization of complex cultural heritage buildings by means of Wearable Mobile Mapping Systems (WMMS) (di Filippo et al., 2018). These systems are able to reconstruct 3D complex environments without the needed of a Global Positioning System, using to this end the Simultaneous Localization And Mapping approach (SLAM) (Durrant-Whyte and Bailey, 2006). This technique employs the data provided by a line laser scanner and a Inertial Measurement Unit (IMU) to solve the pose of the device in each period of time and thus to project, in a common coordinate system, the data captured by the laser head (di Filippo et al., 2018; Nocerino et al., 2017). Among the potentialities of this technology highlights its portability, allowing to obtain a point cloud of a complex environment with centimetric accuracy in a short time (Cabo et al., 2018; di Filippo et al., 2018; Lagüela et al., 2018; Nocerino et al., 2017). Finally, yet importantly, the SLAM technique has improved, allowing to get quality in the trajectory and 3D mapping of the building based on specific algorithms and protocols (Nocerino et al., 2017; Sammartano and Spanò, 2018). In fact, WMMS has been applied for different heritage purposes: Zlot et al., (2014) used a handheld mobile 3D laser mapping system to digitalize complex heritage sites; Dewez et al., (2017) applied Zeb-Revo systems to map an underground historical quarry and its above-ground surroundings; Eyre et al. (2016) evaluated WMMS for historical mining and civil engineering applications. In addition, several authors have compared the accuracy of WMMS and TLS (Cabo et al., 2018; di Filippo et al., 2018; Lagüela et al., 2018; Nocerino et al., 2017) providing good quality, especially when the site is complex and a great amount of laser scan stations are required. However, up to now, there are no studies for the structural analysis of historical buildings using WMMS. Under this basis, the present paper will show a comparative study between WMMS and TLS for the structural evaluation of the barrel vault of a Romanesque church. This comparison will be carried out at different levels: from the performance during the data acquisition to the discrepancies obtained by two numerical models: one built from the data

\footnotetext{
* Corresponding author
} 
captured by the WMMS and another one built from the data captured by the TLS device.

The paper is structured as follows: after the introduction, section 2 describes the LiDAR systems used to digitalize the historical construction and the case study. Section 3 exposes the digitalization of the structure, confronting the time spent to digitalize the whole structure, as well as an accuracy assessment considering the TLS as ground truth. Section 4 analyses the structural stability of the barrel vault of a Romanesque church by means of the Finite Element Method (FEM). Finally, in Section 5 conclusions are drawn.

\section{EQUIPMENT AND CASE STUDY}

\subsection{Equipment}

The equipment used to perform this study included two LiDAR devices: i) a wearable mobile mapping system (WMMS) and; ii) a terrestrial laser scanner (TLS); as well as several registration spheres.

\subsubsection{Wearable Mobile Mapping System}

The WMMS used for the present study case was the ZEB-REVO mobile mapping system. This system is commercialized by the company GeoSLAM (GEOSLAM, 2019). It integrates a 2D rotating laser scanner head, more specifically the Hokuyo UTM30LX-F (Hokuyo Automatic Co., Ltd. Osaka, Japan) rigidly coupled to an IMU on a rotary engine. The data captured by both sensors, Hokuyo laser and the IMU, is stored in a processing unit located in a small backpack (Figure 1a). All these devices are carried by an operator whose movement provides the third dimension required to generate the $3 \mathrm{D}$ point cloud.

This system is able to perform a data acquisition within a default range of $0.60-30 \mathrm{~m}$ indoors and 0.60 to $15 \mathrm{~m}$ outdoors, with a data acquisition rate of 40,000 points per second (Table 1). This device is also equipped with a GoPro camera that allows recording a video at the same time that the laser is capturing the scene.

a)

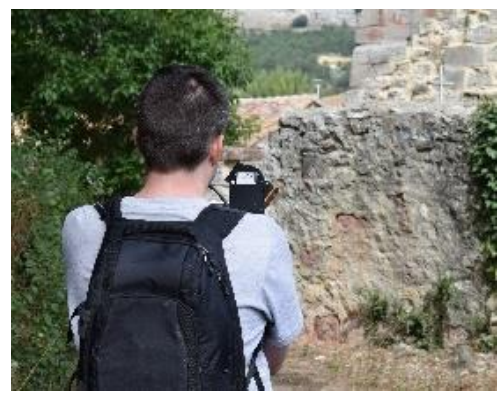

b)

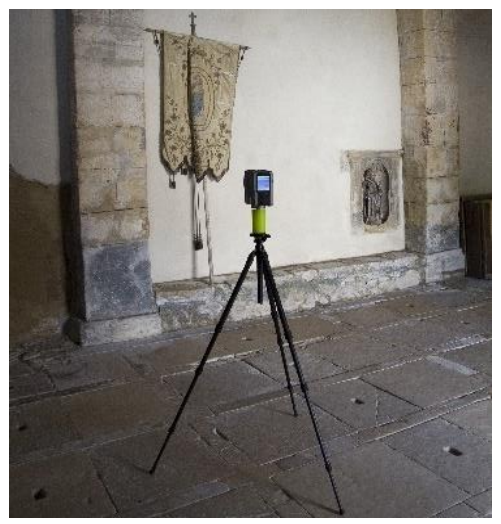

Figure 1. LiDAR devices used to digitalize the church: a) the WMMS Zeb-Revo and; b) the TLS Faro Focus 120.

\begin{tabular}{|l|c|}
\hline Parameter & Value \\
\hline Operating time & 4 hours \\
Dimensions of the & $220 \times 180 \times 470 \mathrm{~mm}$ \\
equipment & \\
Total device weight & $4.10 \mathrm{~kg}$ \\
Measuring principle & Time of flight \\
Wavelength & $905 \mathrm{~nm}$-near infrared \\
Field of view & $270^{\circ}(\mathrm{H}) \times 360^{\circ}(\mathrm{V})$ \\
Accuracy & $1-3 \mathrm{~cm}$ \\
\hline
\end{tabular}

Table 1. Technical specifications of the WMMS, Zeb-REVO, used.

Once the data was captured, a 3D SLAM algorithm was used to combine the data coming from the 2D laser unit with the IMU data, in order to obtain an accurate 3D point cloud of the church. To this end, it was used the full SLAM approach implemented in the robotic operative system (ROS) library (Quigley et al., 2009). This algorithm is based on an incremental solution in which the segments of the 2D laser scanner are registered one-by-one, extracting and matching the geometrical features of these segments as well as the data coming from the IMU sensor. Considering that the previous process is an incremental procedure, in which each segment is aligned with respect to the previous one, an error accumulation could be performed. In order to minimize this error accumulation, a global registration was carried out considering that the starting and ending point are the same (closed-loop solution).

\subsubsection{Terrestrial Laser Scanner}

To evaluate the performance of the WMMS employed for this work, the TLS FARO Focus 3D was used as reference (Figure 1b). This static laser scanner, based on the Amplitude Modulated Continuous Wave (AMCW) phase-based principle, highlights for its portability and fast data acquisition, allowing a capture rate comprised between 122,00 and 976,000 points per second. The most relevant features of this TLS are specified in Table 2.

\begin{tabular}{|c|c|}
\hline Parameter & Value \\
\hline Total device weight & $5.00 \mathrm{~kg}$ \\
\hline $\begin{array}{l}\text { Dimensions of the } \\
\text { device }\end{array}$ & 241 x 203 x $101 \mathrm{~mm}$ \\
\hline Measuring principle & $905 \mathrm{~nm}$ - near infrared \\
\hline Measure range & $0.6-120 \mathrm{~m}$ \\
\hline Field of view & $360^{\circ}(\mathrm{H}) \times 320^{\circ}(\mathrm{V})$ \\
\hline $\begin{array}{l}\text { Accuracy nominal } \\
\text { value at } 25 \mathrm{~m}\end{array}$ & $2 \mathrm{~mm}$ \\
\hline $\begin{array}{l}\text { Spatial resolution at } \\
10 \mathrm{~m}\end{array}$ & $6 \mathrm{~mm}$ \\
\hline
\end{tabular}

Table 2. Technical specifications of the TLS, Faro Focus 3D.

With the aim of aligning the point clouds obtained in each scan station, a network of registration spheres was used. This network was designed by 5 spheres with a diameter of $200 \mathrm{~mm}$ and another 5 spheres with a diameter of $145 \mathrm{~mm}$ (Figure 2). To detect the centroid of each registration sphere the RANSAC Shape Detector algorithm (Schnabel et al., 2007) was used. Then, a rigid transformation (6 parameter Helmert) was applied in order to register the TLS point clouds in a unique coordinate system. It is worth mentioning that the same sphere network was captured by the WMMS solution, allowing the registration of the data in a unique coordinate system. 


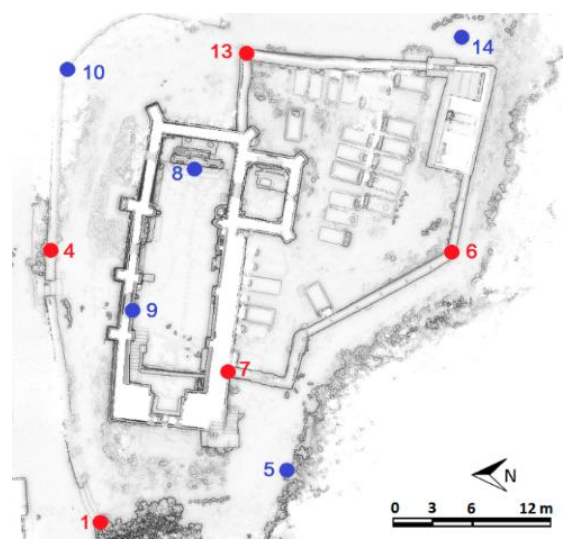

Figure 2. The network of registration spheres. In red the spheres with a diameter of $200 \mathrm{~mm}$ and in blue those with a diameter of $145 \mathrm{~mm}$.

\subsection{Case study: the church of San Pedro (Becerril del Carpio, Palencia)}

With the purpose of evaluating the suitability of the WMMS solution, the church of Saint Pedro was used as case study. This catholic temple is located at the municipality of Becerril del Carpio in Palencia (Spain). A great part of this building was erected in Romanesque style (S-XIII), showing some constructive elements in the late-Gothic.

Regarding its constructive configuration, Saint Pedro shows a single main nave solved by means of a barrel vault and a groin vault with eight sides. Both constructive systems rest in two supports erected with different masonry typologies (regular and irregular sandstone masonries) (Figure 3a). The roof of the church was executed by means of a timber structure which stands a roof of ceramic tiles. However, although the church shows an efficient arrangement from a constructive point of view, the stiffness of the soil on which it is founded has promoted a differential settlement along its main nave, suffering visible deformations and cracks along the main nave, choir and front façade (Figure 3b).

a)

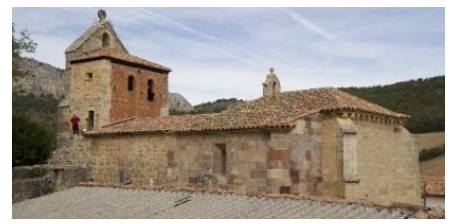

b)

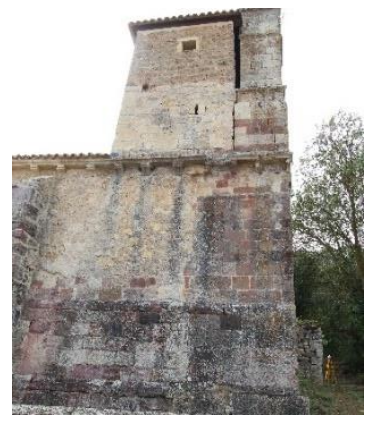

Figure 3. Saint Pedro church: a) general view of the building and; b) detail view of the main tower where is evidenced the presence of visible deformations, plastic hinges and cracks.

In 2007 a monitoring system was installed on the church with the aim of evaluating the movements of the structure. Later, in 2011 a restoration project was carried out on the church. This intervention had the aim of recovering the continuity of the structure, retrofitting the cracks and reinforced the north foundation with a concrete solution. Additionally to this, it was placed on the vault's extrados a fibre reinforced mortar made up by carbon fibres inserted in an inorganic matrix.

\section{DIGITALIZATION OF THE STRUCTURE}

\subsection{Digitalization of the church by means of the WMMS}

Previously to the data acquisition with the WMMS device, an onsite inspection was carried out with the aim of designing the most proper data acquisition protocol. During this inspection it was considered the suggestions proposed by di-Filippo et al. (di Filippo et al., 2018):

- Ensuring the accessibility to all the areas.

- Removing obstacles along the way.

- Planning a closed-loop in order to compensate for the error accumulation.

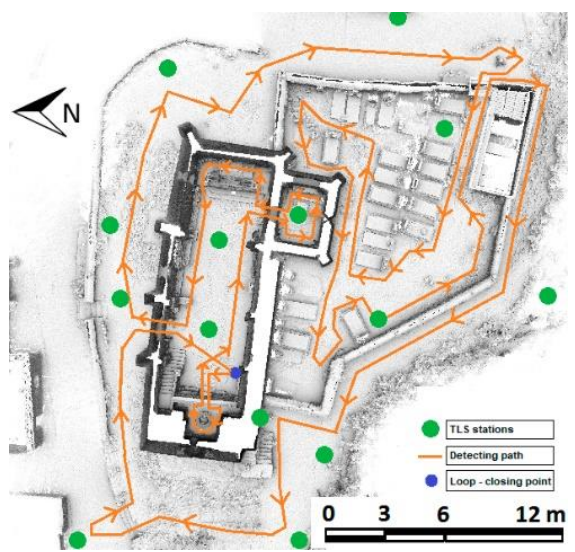

Figure 4. Closed-loop used to digitalize the whole construction.

The green dots indicate the TLS stations carried out.

a)

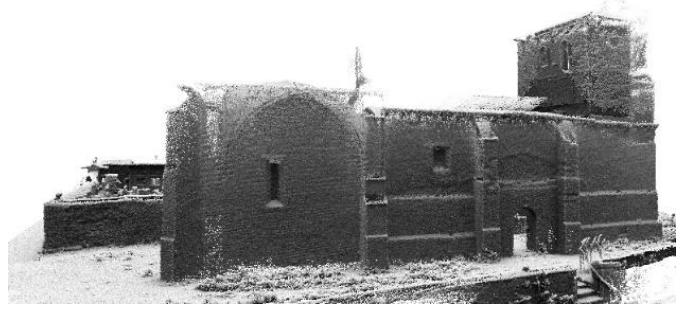

b)

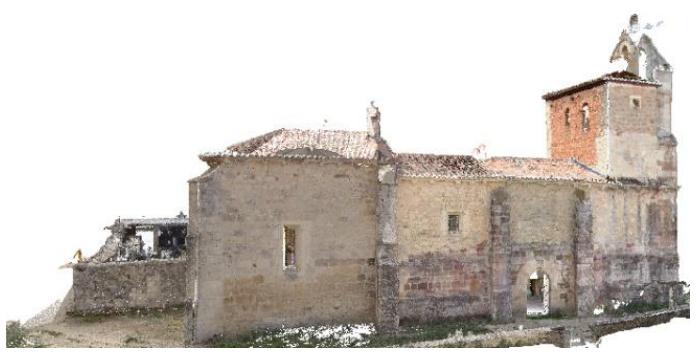

Figure 5. General view of the point clouds obtained: a) the WMMS point cloud and; b) the TLS point cloud. 
As a result of this on-site inspection, a unique closed-loop to digitalize the whole church was considered, investing a total of 16 min (Figure 4). The resultant point cloud was made up of a total of 27 million points (Figure 5a).

Once the data was acquired, a full 3D-SLAM approach was used in order to obtain the 3D representation of the construction, investing a total of $18 \mathrm{~min}$.

\subsection{TLS point cloud}

Complementary to the WMMS data acquisition, a TLS network was carried out with the aim of obtaining a 3D point cloud of the church. The geometrical model obtained by this device will be used as the ground truth, allowing a comparison between the WMMS and the TLS. As a result, it was required 15 scan stations to digitalize the whole building (one of them inside the tower) (Figure 4): i) 4 scans to digitalize the inner space of the church and; ii) 11 scans to capture the outdoors of the church; investing $135 \mathrm{~min}$. The alignment of the different scan-stations was carried out by means of a target-based registration approach, using the registration spheres placed during the data acquisition (Figure 2). During this phase, it was required 120 mins. In order to reduce the high density of the global point cloud in overlap areas, a decimation filter of $0.01 \mathrm{~m}$ was applied, obtaining a point cloud of 33 million points (Figure 5b).

\subsubsection{Accuracy assessment}

Once both point clouds were obtained and registered, an accuracy assessment between both products was carried out. In this case, it will be used as indicators the discrepancies between the centroid's distances of the registration spheres, the following indexes (Nocerino et al., 2017): i) the relative measurement error (RME) (1) and; ii) the relative measurement accuracy (RMA) (2) by means of the extraction of several longitudinal and transversal sections (Figure 6).

The error obtained between both LiDAR technologies, confronting the distances between centroids, was about $0.03 \%$ (Table 3), highlighting the robustness of the WMMS solution and being in line with other experimental campaigns carried out with this sensor (di Filippo et al., 2018).

$$
\begin{gathered}
\operatorname{RME}=\left(\frac{\mathrm{D}_{W M M S}-\mathrm{D}_{T L S}}{\mathrm{D}_{T L S}}\right) \times 100 \\
\operatorname{RMA}=1: \operatorname{ROUND}\left(\left|\frac{100}{\operatorname{RME}}\right|\right)=1: \operatorname{ROUND}\left(\left|\frac{\mathrm{D}_{T L S}}{\mathrm{D}_{W M M S}-\mathrm{D}_{T L S}}\right|\right)
\end{gathered}
$$

where $\quad D_{z}=$ Measured Distance for WMMS system

\begin{tabular}{|c|c|c|c|c|}
\hline & \multicolumn{4}{|c|}{ Distance } \\
\hline & \multirow{2}{*}{$\begin{array}{c}\text { TLS } \\
D_{T L S}(\mathrm{~m})\end{array}$} & \multicolumn{3}{|c|}{ WMMS } \\
\hline & & $D_{\text {WMMS }}(\mathrm{m})$ & RME (\%) & RMA \\
\hline $1-8$ & 28.801 & 28.810 & 0.0312 & $\sim 1: 3200$ \\
\hline $1-13$ & 38.210 & 38.219 & 0.0236 & $\sim 1: 4200$ \\
\hline $4-7$ & 18.066 & 18.077 & 0.0609 & $\sim 1: 1600$ \\
\hline $5-8$ & 24.968 & 24.976 & 0.0320 & $\sim 1: 3100$ \\
\hline $5-13$ & 32.594 & 32.603 & 0.0276 & $\sim 1: 3600$ \\
\hline $6-8$ & 21.272 & 21.268 & -0.0188 & $\sim 1: 5300$ \\
\hline $8-14$ & 22.953 & 22.963 & 0.0436 & $\sim 1: 2300$ \\
\hline \multicolumn{3}{|c|}{ Average } & 0.0286 & $\sim 1: 3300$ \\
\hline
\end{tabular}

$$
\mathrm{D}_{\mathrm{f}}=\text { Measured Distance form TLS system }
$$

Table 3. Discrepancies between the distances obtained by the centroids's spheres in the WMMS point cloud $\left(D_{T L S}\right)$ and in the TLS point cloud (D wммS).
Complementary to this accuracy assessment, several measures were taken from different sections carried out on the construction (Figure 6 and 7). Result of this comparison (Table 3 and 4) it was possible to conclude that the digitalization carried out by means of the WMMS showed a discrepancy of $0.8 \mathrm{~cm}$ (in terms of average error) with respect to the TLS digitalization.

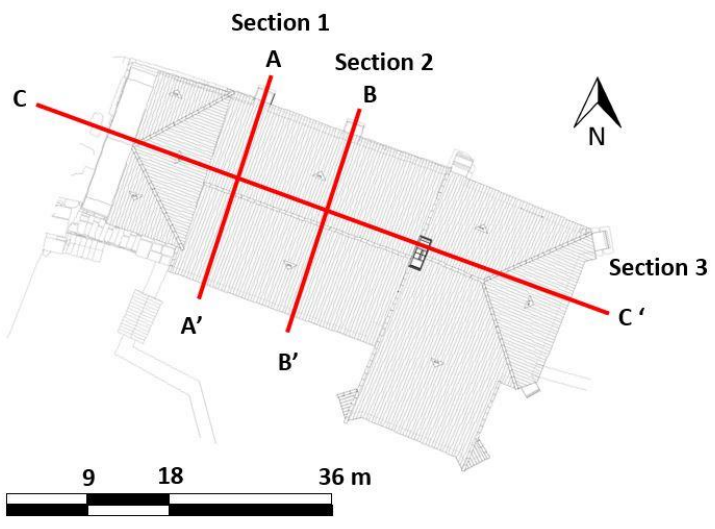

Figure 6. Transversal and longitudinal sections considered for the accuracy assessment.

a)

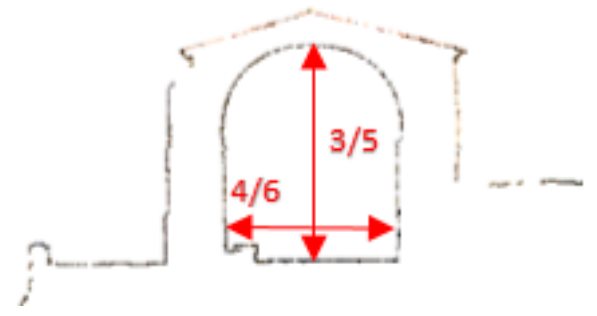

b)

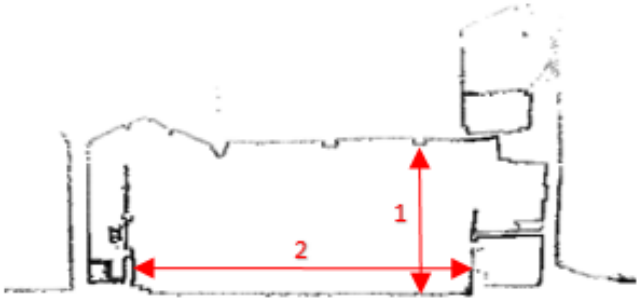

\begin{tabular}{|c|c|c|c|c|}
\hline & \multicolumn{4}{|c|}{ Distance } \\
\hline & \multirow{2}{*}{$\frac{\text { TLS }}{D_{T L S}(\mathrm{~m})}$} & \multicolumn{3}{|c|}{ WMMS } \\
\hline & & $D_{\text {WMMS }}(\mathrm{m})$ & $\begin{array}{l}\text { Absolute } \\
\text { error (m) }\end{array}$ & RME (\%) \\
\hline 1 & 7.234 & 7.236 & 0.002 & 0.028 \\
\hline 2 & 16.286 & 16.298 & 0.012 & 0.074 \\
\hline 3 & 5.824 & 5.829 & 0.005 & 0.086 \\
\hline 4 & 7.260 & 7.254 & 0.006 & -0.083 \\
\hline 5 & 5.706 & 5.703 & 0.003 & 0.053 \\
\hline 6 & 7.168 & 7.182 & 0.014 & 0.195 \\
\hline \multicolumn{3}{|c|}{ Average } & 0.007 & 0.06 \\
\hline
\end{tabular}

Figure 7. Distances considered during the accuracy assessment: a) section $\mathrm{A}$ and; b) longitudinal section.

Table 4. Absolute error between distances ( $\left.D_{T L S}, D_{W M M S}\right)$ obtained in the different longitudinal and transversal sections carried out. 


\section{STRUCTURAL ANALYSIS}

Understanding the barrel vault as a finite succession of arches along its traces, the stability of this construction system can be explained by means of the stability of each arch (Heyman, 1966; Huerta Fernández, 2001). Under this basis, and taking into consideration the digitalization provided by the WMMS and the TLS, the stability of the San Pedro barrel vault was evaluated by means of the FEM. To this end, a plane strain analysis approach was chosen considering the geometrical results obtained by both LiDAR systems.

\subsection{Modelling considerations}

According to the visual inspection carried out during the field campaign, the barrel vault of the San Pedro church was made up by a regular ashlar masonry, an irregular masonry on the vertical walls and a regular masonry on the buttresses (Figure 8).

a)

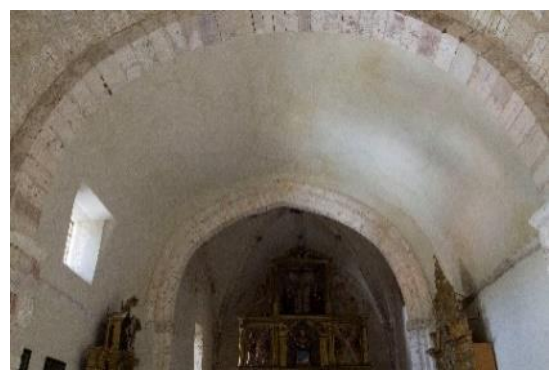

b)

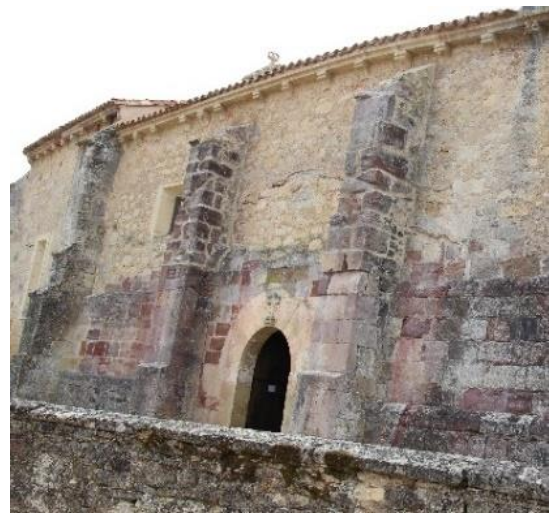

Figure 8. Detail view of the north wall of the San Pedro's church: a) general view of the barrel vault on which is possible to observe geometrical deformations in form of plastic hinges and; b) detail view of the north wall on which is possible to observe a mixture of masonries.

It is worth mentioning that one of the main limitations of the WMMS evaluated is the impossibility of capturing point clouds with RGB or intensity values, hindering the use of a micromodelling strategy to simulate the masonry. Thus, a macromodelling approach was used. Particularly, the masonry was modelled as a continuum and homogeneous material with average properties, thus without making distinction between blocks, joints and interfaces block-joint. Masonry mechanical behaviour was represented by means of a model that considers a post-peak exponential softening for the tensile behaviour and a parabolic hardening followed by a post-peak parabolic softening for compression. The Young Modulus of each masonry component was obtained by means of the Table C8A.2.2 of the Italian standard NTC 2008 (Ministerio delle infrastructure e dei trasporti, 2008). For the inelastic properties of the masonry, it was considered the following assumptions (Table 5): i) a compressive strength value of 1000 times the corresponding Young Modulus, as proposed by Tomazevic et al. (1999); ii) a ductility in compression of $1.60 \mathrm{~mm}$ (Lourenço, 2009); iii) a tensile strength equal to $5.00 \%$ of the compressive strength and; iv) a fracture energy in the tensile regime of $0.05 \mathrm{~N} / \mathrm{mm}$ as proposed in Sánchez-Aparicio et al. (2019).

\begin{tabular}{|c|c|c|}
\hline Parameter & \multicolumn{2}{|c|}{ Value } \\
\hline $\begin{array}{c}\text { Young Modulus } \\
(\mathrm{GPa})\end{array}$ & 1.98 & 1.44 \\
\hline $\begin{array}{c}\text { Poisson ratio } \\
(-)\end{array}$ & 0.20 & 0.20 \\
\hline $\begin{array}{c}\text { Density } \\
\left(\mathrm{kg} / \mathrm{m}^{3}\right)\end{array}$ & 2100 & 2000 \\
\hline $\begin{array}{c}\text { Tensile strength } \\
\left(\mathrm{N} / \mathrm{mm}^{2}\right)\end{array}$ & 0.10 & 0.07 \\
\hline $\begin{array}{c}\text { Fracture energy in } \\
\text { tensile regime } \\
\left(\mathrm{N} * \mathrm{~mm}^{*}\right)\end{array}$ & 0.05 & 1.44 \\
\hline $\begin{array}{c}\text { Compressive } \\
\text { strength } \\
\left(\mathrm{N} / \mathrm{mm}^{2}\right)\end{array}$ & 3.17 & 2.30 \\
\hline $\begin{array}{c}\text { Fracture energy in } \\
\text { compressive regime } \\
(\mathrm{N} * \mathrm{~mm})\end{array}$ & & \\
\hline \multicolumn{2}{|c|}{}
\end{tabular}

Table 5. Values adopted for modelling masonry.

\begin{tabular}{|c|c|}
\hline Parameter & Value \\
\hline $\begin{array}{c}\text { Young Modulus } \\
(\mathrm{GPa})\end{array}$ & 0.30 \\
\hline $\begin{array}{c}\text { Poisson ratio } \\
(-)\end{array}$ & 0.20 \\
\hline $\begin{array}{c}\text { Density } \\
\left(\mathrm{kg} / \mathrm{m}^{3}\right)\end{array}$ & 1700 \\
\hline $\begin{array}{c}\text { Friction angle } \\
(\text { degrees })\end{array}$ & 20 \\
\hline $\begin{array}{c}\text { Cohesion } \\
(\mathrm{kPa})\end{array}$ & 20 \\
\hline
\end{tabular}

Table 6. Values adopted for modelling the vault's infill.

Regarding the infill of the barrel vault, this work has considered a classical Mohr-Coulomb yield criterion. This model is suitable for simulating cohesive materials such as those expected in the vault's infill. Within this context, the mechanical values proposed by Conde et al. (Conde et al., 2017) were used as suitable values for the vault's infill. Table 6 summarizes the values adopted for the numerical simulations of the infill.

\subsection{Numerical mesh}

The geometry captured by both LiDAR devices showed a slight inclination of the vertical walls (Figure 8b). On the one hand, the inclinations of the north support on the TLS point cloud were: i) $1.70^{\circ}$ for the section 1 and; ii) $1.75^{\circ}$ for the section 2 . On the other hand, the WMMS was able to capture an inclination of: i) $1.63^{\circ}$ for the section 1 and; ii) $1.65^{\circ}$ for the section 2 . This deformation pattern is a common pathology in many churches (Block et al., 2006; Huerta Fernández and López Manzanares, 1997) and can be associated to the settlement of the church in the past.

According to Sánchez-Aparicio et al. (2014), the creation of a suitable geometrical model for numerical analysis purposes can be carried out by means of one of the following approaches: i) extraction of orthogonal views and sections along several directions of the point cloud or mesh or; ii) by means of advanced 
surface representation strategies such as the non-uniform bsplines. Taking into consideration that the stability of the barrel vault can be evaluated by means of the stability of each arch within its trace, the first strategy was used. In particular, the Section 2 (Figure 6) was considered for numerical analysis. This section is the most unfavourable one, showing the most leaned supports (the collapse for this typology of structures could come from the inclination of the supports due to the lateral truss generated by the vault).

Complementary to the external envelope captured by both LiDAR devices, the following assumptions were taken into account: i) a cohesive infill until $2 / 3$ of the vault's rise; b) a constant vault thickness of $0.32 \mathrm{~m}$ for the TLS and $0.31 \mathrm{~m}$ for the WMMS. Both values were obtained in a transversal section of the church's tower (Figure 7b).

The final step before the creation of the numerical mesh involved the tracing of the two-dimensional section. To this end, the vectorizing approach defined by di-Fillipo et al. (2018) was used. Those parts without geometrical information (e.g. infill of the vault or areas not captured by the LiDAR devices) were interpolated according to the assumptions previously indicated (Figure 9). Then, two numerical meshes were created (one for the TLS and another one for the WMMS) in order to evaluate this section by means of the FEM. On the one hand, the TLS numerical mesh was made up of 1727 triangular high-order 2D elements with two translational degrees of freedom per node. Meanwhile, the WMMS numerical mesh was made up of 1832 triangular high-order 2D elements. In both numerical meshes, it was considered, at least, two elements in the thickness of the barrel vault and walls to capture the stress gradients that could appear during the non-linear structural analysis.

It is worth mentioning that the reinforced mortar layer added during the last restoration works was not included with the aim of minimizing possible discrepancies due to the non-linear behaviour of this solution and its complex interaction with the masonry vault. For the boundary conditions of the structure, it was assumed pinned supports at the base of the walls according to the intervention carried out during the last restoration action. Concerning the loads acting on the top of the walls, it was assumed a value of $0.2 \mathrm{kN} / \mathrm{m}^{2}$ (approximately the weight of the rafters and tiles placed on the roof).

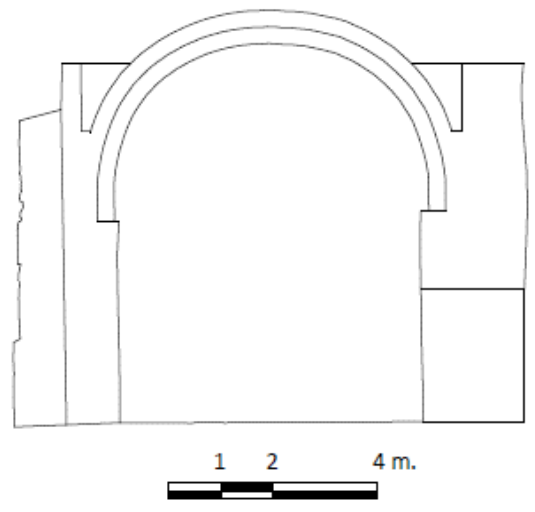

Figure 9. Detail of the section 2 considered for numerical analysis.

\subsection{Structural behaviour against vertical loading}

To evaluate the structural performance of the barrel vault against vertical loading, a non-linear analysis increasing gravitational loading until failure was carried out. For the solution of the non- linear problem, an arch length control scheme complemented by the line-search technique was adopted.

Result of this, it was possible to estimate the safety factor of the structure (Table 7). In the case of considering the TLS point cloud, the safety factor of the vault was 5.37. Meanwhile, with the WMMS the safety factor obtained was 5.20, exiting a discrepancy of about $3 \%$ between both LiDAR devices. In both cases, the collapse mechanism takes place with the inclination of both supports and the alignment of three hinges formed in the vault (Table 7) (Figure 10).

\begin{tabular}{|c|c|c|}
\hline & Safety factor & Collapse topology \\
\hline TLS & 5.37 & $\begin{array}{c}\text { Alignment of } 3 \text { hinges and } \\
\text { support inclination }\end{array}$ \\
\hline WMMS & 5.20 & $\begin{array}{c}\text { Alignment of 3 hinges and } \\
\text { support inclination }\end{array}$ \\
\hline
\end{tabular}

Table 7. Comparison of the results obtained from the FEMbased numerical models.

a)

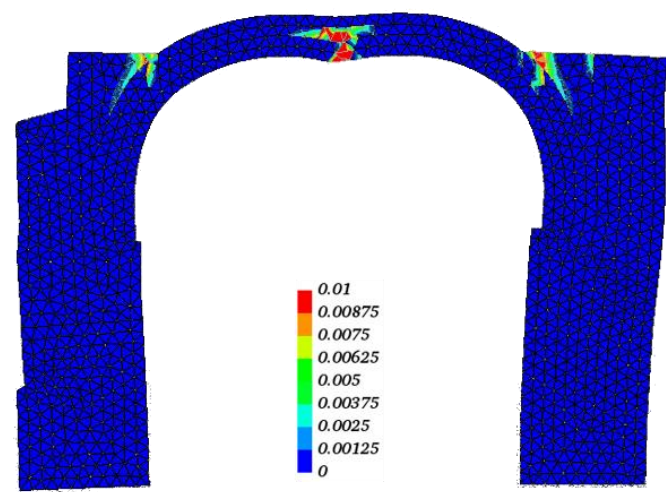

b)

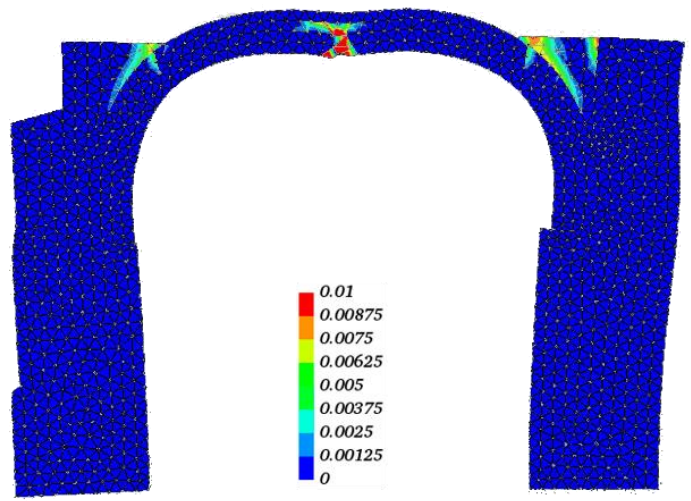

Figure 10. Collapse mechanism obtained in section B-B`a) in the TLS point cloud and; $b$ ) in the WMMS point cloud. The figures express the maximum principal strains (indicator of cracking).

\section{CONCLUSIONS}

Through this article, we have advanced a novel line based on the application of WMMS data as input for the structural analysis of historical buildings. The results obtained during the present campaign, in terms of data acquisition, processing and results of the numerical evaluations place this sensor as an attractive solution for the structural analysis of historical constructions. From the case evaluated, the sensor is able to save around 7.5 times the time required to digitalize the construction by means of TLS, obtaining an accuracy of about $0.8 \mathrm{~cm}$ and a discrepancy of $0.09^{\circ}$ in the evaluation of the support's inclinations. With respect 
to the numerical evaluation carried out, it was possible to observe a discrepancy of about $3 \%$ between the developed numerical models. All this data places this solution as a potential sensor, especially if the construction shows a complex distribution of spaces for which it is expected that the performance ratio between the WMMS and the TLS performance will increase.

Further investigations will be focused on analyzing the suitability of the portable solution for the creation of 3D advance numerical simulations by means of the finite element method and the latest advances in reverse engineering. To this end, it will be required and evaluation of several noise reduction filters, such as the Moving Least Squares or the Statistical Outlier Removal, several meshing strategies as the Delaunay or Poisson strategies as well as surface methods (NURBS and Loft surfaces). Additionally, it will be evaluated the possibility of colouring the point cloud obtained by the Zeb-REVO laser scanner with the aim of evaluating the construction by means of a micromodelling approach.

\section{ACKNOWLEDGEMENTS}

This work was financed by ERDF funds through the V SUDOE INTERREG program within the framework of the HeritageCARE project, Ref. SOE1/P5/P0258 and the research project Patrimonio 5.0 funded by Junta of Castilla y León, Ref. SA075P17. First author would like to thank the University of Salamanca for the program for human resources "Programa II: Contratos Postdoctorales".

\section{REFERENCES}

Bautista-De Castro, Á., Sánchez-Aparicio, L.J., Ramos, L.F., Sena-Cruz, J., González-Aguilera, D., 2018. Integrating geomatic approaches, Operational Modal Analysis, advanced numerical and updating methods to evaluate the current safety conditions of the historical Bôco Bridge. Construction and Building Materials, 158, pp. 961-984.

Block, P., Ciblac, T., Ochsendorf, J., 2006. Real-time limit analysis of vaulted masonry buildings. Computers \& structures, 84, pp. 1841-1852.

Cabo, C., Del Pozo, S., Rodríguez-Gonzálvez, P., Ordóñez, C., González-Aguilera, D., 2018. Comparing terrestrial laser scanning (TLS) and wearable laser scanning (WLS) for individual tree modeling at plot level. Remote Sensing, 10 (4), 540.

Conde, B., Ramos, L.F., Oliveira, D.V., Riveiro, B., Solla, M., 2017. Structural assessment of masonry arch bridges by combination of non-destructive testing techniques and threedimensional numerical modelling: Application to Vilanova bridge. Engineering Structures, 148, pp. 621-638.

Charter of Krakow, 2000. Principles for conservation and restoration of built heritage http://smartheritage.com/wpcontent/uploads/2015/03/KRAKOV-CHARTER-2000.pdf (25 June 2019).

Del Pozo, S., Sánchez-Aparicio, L., Rodríguez-Gonzálvez, P., Herrero-Pascual, J., Muñoz-Nieto, A., González-Aguilera, D., Hernández-López, D., 2015. Multispectral imaging: Fundamentals, principles and methods of damage assessment in constructions. Non-Destructive Techniques for the Evaluation of Structures and Infrastructure. CRC-Press, Florida, pp. 139-166.
Dewez, T.J., Yart, S., Thuon, Y., Pannet, P., Plat, E., 2017. Towards cavity-collapse hazard maps with Zeb-Revo handheld laser scanner point clouds. The Photogrammetric Record, 32, pp. 354-376.

di Filippo, A., Sánchez-Aparicio, L., Barba, S., Martín-Jiménez, J., Mora, R., González Aguilera, D., 2018. Use of a Wearable Mobile Laser System in Seamless Indoor 3D Mapping of a Complex Historical Site. Remote Sensing, 10 (12):1897.

Durrant-Whyte, H., Bailey, T., 2006. Simultaneous localization and mapping: part I. IEEE robotics \& automation magazine, 13(2), pp. 99-110.

Ministerio delle infrastructure e dei trasporti, 2008. Norme tecniche per le costruzioni. Ministero delle Infrastrutture e dei Trasporti, Decreto Ministeriale del 14 http://www.cslp.it/cslp/index.php?option=com_content\&task=vi ew\&id=66\&Itemid=1 (25 June 2019).

Eyre, M., Wetherelt, A., Coggan, J., 2016. Evaluation of automated underground mapping solutions for mining and civil engineering applications. Journal of Applied Remote Sensing, 10.

GEOSLAM, 2019. ZEB-REVO Solution Brochure https://gpserv.com/wp-content/uploads/2017/01/ZEB-REVOBrochure-v1.0.3.pdf (25 June 2019).

Heyman, J., 1966. The stone skeleton. International Journal of solids and structures, 2, pp. 249-279.

Huerta Fernández, S., 2001. Mechanics of masonry vaults: The equilibrium approach http://oa.upm.es/569/ (25 June 2019).

Huerta Fernández, S., López Manzanares, G., 1997. Stability and consolidation of an ashlar barrel vault with great deformations: the church of Guimarei http://oa.upm.es/568/ (25 June 2019).

Lagüela, S., Dorado, I., Gesto, M., Arias, P., González-Aguilera, D., Lorenzo, H., 2018. Behavior analysis of novel wearable indoor mapping system based on 3d-slam. Sensors, 18 (3).

Lourenço, P., 2009. Recent advances in masonry structures: Micromodelling and homogenisation. Multiscale Modeling in Solid Mechanics: Computational Approaches. Imperial College Press, London, pp. 251-294.

Nocerino, E., Menna, F., Remondino, F., Toschi, I., RodríguezGonzálvez, P., 2017. Investigation of indoor and outdoor performance of two portable mobile mapping systems, Videometrics, Range Imaging, and Applications XIV. International Society for Optics and Photonics, 10332.

Quigley, M., Conley, K., Gerkey, B., Faust, J., Foote, T., Leibs, J., Wheeler, R., Ng, A.Y., 2009. ROS: an open-source Robot Operating System. In: ICRA workshop on open source software, Kobe, Japan, Vol. 3.

Sammartano, G., Spanò, A., 2018. Point clouds by SLAM-based mobile mapping systems: accuracy and geometric content validation in multisensor survey and stand-alone acquisition. Applied Geomatics, 10, pp. 317-339.

Sanchez-Aparicio, L., Rodriguez-Gonzalvez, P., GonzalezAguilera, D., Ramos, L., 2019. Evaluating the Structural Integrity of the Saint Antonio Barrel Vault in the Fortress of Almeida by Combining Laser Scanner and Limit Analysis. In: ISPRS- 
International Archives of the Photogrammetry, Remote Sensing and Spatial Information Sciences 422, Bergamo, Italy, Vol. XLII-2/W9, pp. 679-684, doi.org /10.5194/isprs-archives-XLII2-W9-679-2019.

Sánchez-Aparicio, L.J., Bautista-De Castro, Á., Conde, B., Carrasco, P., Ramos, L.F., 2019. Non-destructive means and methods for structural diagnosis of masonry arch bridges. Automation in Construction, 104, pp. 360-382.

Sánchez-Aparicio, L.J., Del Pozo, S., Ramos, L.F., Arce, A., Fernandes, F.M., 2018. Heritage site preservation with combined radiometric and geometric analysis of TLS data. Automation in Construction, 85, pp. 24-39.

Sánchez-Aparicio, L.J., Riveiro, B., Gonzalez-Aguilera, D., Ramos, L.F., 2014. The combination of geomatic approaches and operational modal analysis to improve calibration of finite element models: A case of study in Saint Torcato Church (Guimarães, Portugal). Construction and Building Materials, 70, pp. 118-129.

Schnabel, R., Wahl, R., Klein, R., 2007. Efficient RANSAC for point-cloud shape detection, Computer graphics forum. Wiley Online Library, pp. 214-226, doi.org/ 10.1111/j.14678659.2007.01016.x.

Tomaževič, M., 1999. Earthquake resistant design of masonry buildings: 40 years after the Banja Luka earthquake. In: International Conference on Earthquake Engineering, pp. 21-33.

Zlot, R., Bosse, M., Greenop, K., Jarzab, Z., Juckes, E., Roberts, J., 2014. Efficiently capturing large, complex cultural heritage sites with a handheld mobile 3D laser mapping system. Journal of Cultural Heritage, 15, pp. 670-678. 